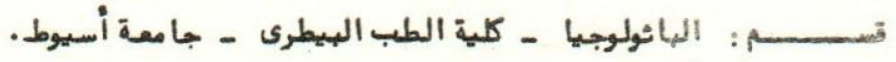

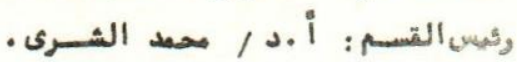

د راسة تجرينية لعد وى الكورينى بكتريم فى خنا زير غينيســــا.

بد الرحمن خاطر، مدلاح ديب، عد اللطيف بيومى ، معد حسيب

أجرى هذ ا البحث لسعرفة هدى وكيفية وكذ لك باثولوجية تأثير ميكروب الكورينى ABU وهو العتر

من جاموس مصاب بمرض الجلد الاود يمى فق جمهيورية مصر العربية.

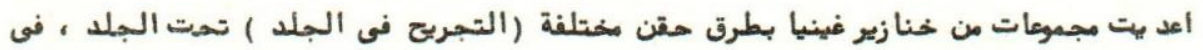

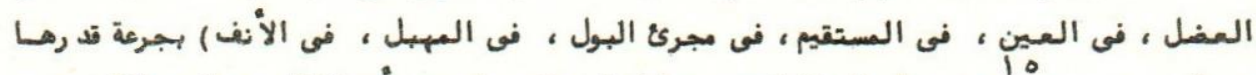

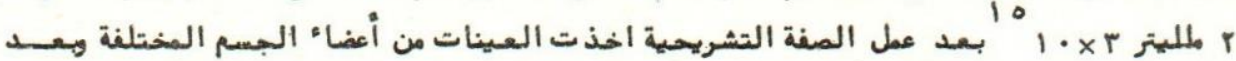

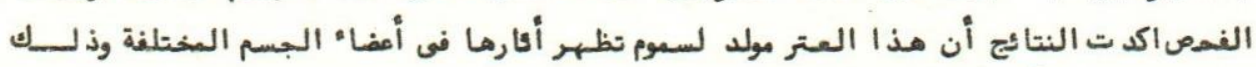

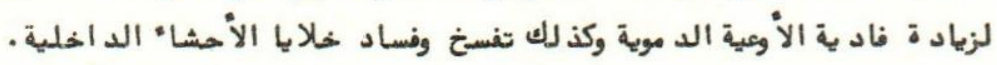


Dept. of Pathology,

Faculty of Vet. Med., Assiut University,

Head of Dept. Frof. Dr. M.I. El-Sherry.

\title{
STUDIES ON EXPERIMENTAL INFECTION WITH CORYNEBACTERIUM PSEUDOTUBERCULOSIS (OVIS) \\ IV- PATHOLOGICAL CHANGES IN GUINEA PIGS. \\ (With 5 Figures)
}

By

A.R. KHATER, S. DEEB, A.H. BAYOUMI and M.M. HASSIEB

(Received at 29/6/1982)

\section{SUMMARY}

\begin{abstract}
In the present work, an experimental study for the corynebacterium pseudotuberculosis-infection was done in order to elucidate its pathological effects and pathogenesis in guinea pigs, using the strain A Bu 77 isolated from buffaloe cases showing typical lesions of oedematous skin disease.

The animals were infected through different routes, skin scarification, intradermal, subcutaneous, intramuscular, oral, intranasal occular, intravaginal, intraurethral and intrarectal, except for skin scarification, intranasal and occular routes, the infective dose was 0.2 $\mathrm{ml}$. of the organism suspension with a viable count of $3 \times 10$.

According to our results, variation in survival period and severity of infection depend not only on dose and size of the animal, but also on the nature of the infected membrane, vascularity and avialable reticular elements, presence and character of secretion or excretion at the porta of entry, as well as on the character of this organism to be clumped.
\end{abstract}

\section{INTRODUCTION}

Corynebacterium pseudotuberculosis (ovis) was recorded by many workers to produce different lesions in experimental animals using different routes of infection. Local abscess formation and deaths within 1-2 days following subcutaneous inoculation of mice were reported by NOCARD (1896), and MINETT (1922). Von-SACEGHAM (1919) found that subcutaneous inoculation of the organism caused death within 10 days with lesions of pseudotuberculosis. TOBIN and MORSE (1957) found internal organ-lesions in ten out of sixteen strains used, otherwise localized abscesses were observed. ZAKl, (1966) reported that congestion of the subcutaneous vessels, intestinal tract blood vessels, lung and adrenals were the main postmortem changees in intra-peritoneal infection of the mice with the organism while intravenous injection resulted in suppurative osteomyelitis and arthritis. KHATER, et al., (1977) reported that Corynebacterium pseudotuberculosis (ovis) was pathogenic to guinea pigs by all routes of infection and the primary lesions were related to the seat of entery and regional lymph nodes. The authors reflect the behaviour of the organism as pyogenic and toxogenic agent. CARNE and ONON (1978) considered two possible action of the toxin corynebacterium pseudotuberculosis (ovis), the first one was an indirect effect in which the toxin acts on mast cells closely associated with blood vessels, leading to liberation of histamine and 5-hydroxytryptamine which then acts on adjacent endothelial lining membranes of blood vessels increasing their permeablity, and the second was a direct action of the toxin on the endothellal cells.

In the present work, an experimental study for the corynebacterium pseudotuberculosis-infection was don in order to elucidate its pathological effects and pathogenesis in guinea pigs, using the strain A Bu 77 isolated from buffaloe cases showing typical lesions of oedematous skin disease in Egypt.

\section{MATERIAL and METHODS}

A total number of 66 apparently healthy guinea pigs of an average body weight of $400 \mathrm{gm}$. were used. The animals were divided into 10 groups, 5-8 animals each, which were infected with A Bu 77 strain of corynetuberculosis through different routes (skin scarification, intradermal, subcutaneous, intramuscular, oral, intrnasal, occular, intravaginal, intrurethral, and intrarectal). Moreover, a group of 5 animals was used as a control. Except for skin scarification, intranasal and occular routes, the infective dose was $0.2 \mathrm{ml}$. of the organism suspension with a viable count of $3 \times 10$. The experimental period lasted 36 days. 
A.R. KHATER, 트 a․

Post mortem examination was carried out on dead animals and those who survived were sacrificed at the end of the experiment. Tissue specimens from the lung, heart, liver, spleen and kidneys were taken. Moreover, specimens were also taken from the skin at the site of inoculation and from the urogenital tract, digestive tract, adrenals and from the superficial and internal lymph nodes (precrural, mesentric and inguinai).

All specimens were fixed in 10\% formalin solution and embedded in paraffin. Paraffin sections 5-6 u were stained with haematoxylin and eosin, Massons trichrome stain and toluidine blue stain.

\section{RESULTS}

\section{Pathogenicity and gross pathological findings:}

The first deaths occurred as early as 3 days and could be delayed to 30 days postinfection. No deaths occurred in animals infected per os.

Animals infected intradermally, subcutaneously and intramuscularly showed grossly a variable degree of local oedema in the skin and subcutaneous tissue. At incision, gelatinous fluid accumulating at the size of injection was observed. The skin itself was relatively thickened and congested. The regional lymph nodes at the sides at which the animals were inoculated were congested. Examination revealed, moreover, severe congestion of the abdominal organs and adrenals as well as the lungs irrespective of the route of infection. Tiny pale necrotic foci could be demonstrated in the liver of animals died following intramuscular intranasal infection as well as in animals infected per os which were sacrificed at the end of the experiment. Although the internal lymph nodes were inflammed they did not reveal any abscesses or pyogenic foci frossly.

\section{Histopathological findings:}

The animals infected by scarification changes consisted mainly of detachment of localized areas of the epidermis from the underlying layers due to accumulation of oedematous fluid. The collagen bundles were disorganized and swollen. After intradermal inoculation of the microorganism, the epidermis and dermis were totally destroyed and showed a dense localized area of infilteration mainly of neutrophils, at the site of inoculation, while this infiltration was diffuse in other parts. Infiltrating cells were fragmented and the chromatin partickes imparted the lesion an intense basophilic stain. In the epidermis, some cells at the Malpighian layer showed hydropic degeneration. In the dermis espically in the papillary layer cellular infiltration, congestion and naemorrhages by diapedesis, as well as activation of macrophages was demonstrated. In animals infected by subcutaneous inoculation, the epidermal changes were less prominent, the dermal changes were more severe and the subcutis showed focal and diffuse cellular infiltrations, moreover, the subcutaneous muscle bundles undergo degeneration and necrosis. These changes were more severe in these bundles around blood vessels (Fig. 1).

While no changes were demonstrated in regional lymph nodes in animals intected by scarification, they showed oedema and slight congestion in animals infected intradermally. After subcutaneous and intramuscular infection, haemorrhagic lymphadenitis could be observed. Some cortical lymphoid follicles were spared and appeared prominent against surrounding haemorrhagic (Fig. 2). Neutrophils were observed in the paracortical zone in one animal infected intradermally and animals infected by subcutaneous or intramuscular inoculation.

In animals infected either by scarification, intradermally, subcutaneously or intramuscularly, the pulmonary blood vessels and interalveolar capillaries were severely congested (Fig. 3), alveolar lumens showed few number of erthrocytes admixed with finely stranded dirty pink material, and frequently the blood vessels showed intimal degenerative changes, fibrinoid degeneration and perivascular plasma exudation. In severely affected cases proliferation of alveolar epithelium, cellular infiltration around alveolar capillaries, predominently mononuclears and few number of neutrophils, together with the occurrence of a relatively large septal cells and thickening of alveolar septa could be demonstrated. The bronchial and bronchilar lumens at many parts of the lung were filled with desquamated epithelial cells. Loss of metachromasia was evident in the bronchial cartilage in sections stained with toluidine blue. The muscle layer and bronchial cartilage, moreover, showed degeneration and necrosis. Endarteritis oblitrans 


\section{CORYNEBACTERIUM PSEUDOTUBERCULOSIS}

in its early stage could be also occassonally observed. These changes were manifested in animals infected by scarification, intradermal, subcutaneous and intramuscular inoculation in an increasing order respectively.

In animals infected by scarification, the liver was severly congested. The endothelial lining of hepatic blood vessels showed degenerative changes and necrosis. Mild degree of oedema of portal triads and small areas of haemorrhages with no specific lobular distribution were also observed. in animals infected intradermally or by subcutaneous incculation, rupture of hepatic veins led to formationof lakes of blood in the hepatic parenchyma. Degeneration and necrosis of hepatic vessels, oedema and minonuclear cell infiltration of the portal triads were more severe. These changes were accompanied with the occurrence of focal necrotic areas in the hepatic parenchyma in one animal infected intramuscularly (Fig. 4).

In the kidneys, congestion of the vasculat bed associated with haemorrhage by diapedesis in the cortex were a consistent findings in animals infected by scarification, intradermal, subcutaneously or intramuscular inoculation. Tubulonephrosis occurred in animals infected either intradermally or subcutaneously.

In the heart of two animals infected by scarification and in other animals infected intradermally, subcutaneousiy or intramuscularly, degeneration of cardiac muscle fibers, congestion with haemorrhages were observed. In one animal in each of the two groups infected subcutaneously or intramusclarly, inflammatory changes of the endocardium with lymphocytic infiltration was observed.

In all animals infected either per os or intranasaly congestion and endarteritis of pulmonary vessels, desquamation of bronchial epithelial cells, peribronchial lymphoid hyperplasia and degeneration of the bronchial cartilage could be demonstrated. Similar changes were also observed in animals by occular instillation except one, and in two animals infected intrarectally, while the lung in animals infected intravaginally or intraurethrally revealed no detectable changes.

Generally in the liver, animals infected per os, intranasally, by occula instillation, intravaginally, intraurethrally or per rectum, the organ showed congestion and oedema in the portal triads. In one animal infected intranasally and in two animals infected orally changes varying from hydropic degeneration to coagulative necrosis in circumscribed areas could be observed.

The predominent changes in the Kidneys of animals infected per os, intranasally, intravaginally, intraurethrally or per rectum consisted of congestion of blood vessels and tubulonephrosis of variable degrees mainly in the cortex, and extended to involve the collecting tubules of the medull in animals infected intravaginally. Focal areas of non suppurative interstitial nephritis was observed in animals infected either intranasally, intravaginally or intraurethrally. The kidneys in animals infected by occular instillation were more or less normal.

Mild degenerative changes were demonstrated in cardiac muscles in the heart of animals infected by occular instillation or intravaginally. Most the animals infected orally and in one animal infected intranasally showed inflammatory changes manifested by diffuse lymphocytic infiltration of the myocardium. No microscopical lesions were found in other animals of this group or of groups infected intraurethrally or per rectum.

Pathological changes in females infected intravaginally consisted of features of degeneration and occasionally necrosis and desquamation in the lining epithelium of the vagina, cervix and uterus. Changes in the urethra and urinary bladder in these animals were restricted to hydropic degeneration of the epithelial cells.

In male animals infected intraurethrally, the mucosa of the urethra showed necrotic changes through its length. Many of the connective tissue fibers of corpus spongiosum and corpus cavernosum and smooth muscl fibers were hyalinized. In the urinary bladder, the superficial epithelium was desquamated at many locations while the deeper layer frequently showed necrosis.

In the intestine of animals infected per rectum only congestion of the submucosal and serosal vessels could be observed.

The adrenal gland of animals infected either orally, occularally, intramuscularly or by scarification showed congestion, haemorrhage and oedema (Fig. 5). Focal areas of necrosis involving zona fasiculata and zona reticularis were observed in animals infected intravaginally, intraurethrally or per rectum. 


\section{A.R. KHATER, et al.}

Generally, except the mesentric lymph nodes in animals infected per rectum showed rarefaction of lymphoid tissue and degeneration of the reticulum, the internal lymph nodes were only slightly congested and oedematous in animals infected by any one of these 6 routes. The spleen was likewise congested.

\section{DISCUSSION}

Guinea pigs is known to be highly susceptible to experimental infection with C. pseudotuberculosis (ovis). Fetal results of experimentally infected animals were recorded by BULL and DICKINSON (1931), CARNE (1934), SOLIMAN et al., (1963), JOLLY (1965) and KHATER et al., (1977). In the present study, death slso occurred following infection in guinea pigs as early as 3-4 days and was delayed up to 30 days. In this animal species, variation survival period using one and the same strain adminstrated by different routes were also reported by SOLIMAN et al., (1963) and KHATER et al., (1977). Similar results were also obtained by SOLIMAN et al., (1963) by intraderms inoculation of different strains.

In mice, death within 24 to 48 hours was recorded by NOCARD (1986) an within 10 days by MINETT (1922), following subcutaneous inculation of C. pseudotuberculosis, while PURCHASE (1940) showed that intramuscular injection of this organism killed mice between 17-21 days. No deaths during an experimental period of 14 days following intraperitoneal or intravenous inoculation were recorded by MORSE (1957) in mice.

According to our results, variation in survival period and severity of infection depend not only on dose and size of the animal, but also on the nature of infected membranes or epithelial lining, vascularity and available lymphoreticular elements, presence and character of secretion or excretion at the porta of entry, as well as on the character of this organism to be ciumped. Survival of animals infected per os in the present study is thought to be related to the nature of exotoxin produced by this organism as it is known that most of the protein toxin (exotoxin) is in-effective by the oral route. Presumably because they are destroyed in the gut, or fail to penetrate the mucosa (TOPLEY and WILSON, 1977).

JOLLY (1965) postulated that intoxication with exotoxin of C. pseudotuberculosis \& ovis) is an important contributing factor in acute disease. Features of intoxication were observed in our experimental animals consisting of congestion, haemorrhage, oedema as well as degenerative changes in parenchymatous organs. These changes, occasionally associated with adrenal necrosis, therefore acute adrenal insufficiency which may aggrevate the condition, possibly are responsible for death.

The present work indicated that vascular changes in the form of vasodilatation and increased permeablity resulted from a primary effect of the toxin on the wall of blood vessels and it is improbable that products of damaged tissue or leucocytes play an important role in the early stages. In addition, changes occurred in conditions of nephrosis, myocardiosis and degeneration of subcutaneous muscles could be considered as a primary effect of the toxin. The latter, as well, may be responsible for an exfoliative effect manifested by desquamation of alveolar epithelium and epitheliallining of respiratory and urogenital tracts. The present study also emphasized our earlier observation in buffalo, cattle and sheep on the presence of substance (s) which kills leucocytes without lysis which is parallel to the suggestion of MADY (1953) that C. pseudotuberculosis produces leucocidin. Areas of hepatic necrosis as well as necrotic changes in the adrenal glands observed in some of our experimental animais are thought partly to be secondary to vascular changes, these areas were focal and circumscribed.

\section{REFERENCES}

Bull, L.B. and Dickinson, C.G. (1935): Aust. Vet. J., 2, 126, Cited by Zaki, M.M., (1976).

Carne, H.R. (1934): D.v.Sc. Thesis, University of Sydoney. Cited by Jolly, R.D. (1965).

Carne, H.R. and Onon, E.O. (1978): Action of C. ovis exotoxin on endothelial celis of blood vessels. Nature, UK, 271, 246-248.

Jolly, R.D. (1965): The pathogenic action of the exotoxin of C. ovis. J. Comp. Path., 75, 417-431.

Jolly, R.D. (1965): The Pathogenesis of experimental C. ovis infection in mice. N.Z. Vet. J., 13, 141-147. 
Khater, A.R., Sherry, M.I. and Barakat, A.A. (1977): The pathogenesis of C. ovis in guinea pigs. Assiut Vet. J., 4, 89-100.

Maddy, K.T. (1953): Corynebacterium paeudotuberculosis infection in horse. J. Amer. Vet. Med. Ass., $122,257$. Maddy, K.T. (1953): Caseous lymphadenitis of sheep. J. Amer, Vet. Med. Ass., 122, 257-259.

Minett, F.C. (1922): J. Comp. Path. Cited by Jolly, R.D. (1965).

Nocard, E. (1896): Sur une lymphangite ulcereuse. Ann. Inst. Past. 10, 609.

Purchase, H.S. (1944): An outbreak of ulcerative lymphangitis in cattle caused by C. ovis. J. Comp. Path. Therap., 54, 238-244.

Soliman, K.N., Agamy, F.I. and Soyour, E.M. (1963): Bacteriological study of twenty five strains of C. ovis. Proceeding 4th Arab Annual Vet. Congress., 99-107.

Tobin, A.J. and Morse, E.v. (1957): The pathogenesity of C. pseudotuberculosis for laboratory white mice. Cornell Vet., $47,413$.

Toply, W.W.C. and Wilson, G.S. (1975): Principals of Bacteriology, Virology and Immunity, 6th ed. London.

Von-Sagegham, R. (1919): Bull. Soc. Pat. Exct. 12.9 Cited by Toply, W.W.C. andWilson, G.S. (1975).

Zaki, M.M. (1966): The ability of C. ovis to produce suppurative osteomylitis and arthritis in white mice. J. Comp. Path., 76, 121-126.

Zaki, M.M. (1976): Relation between the toxogenicity and pyogenicity of C. ovis in experimentally infected mice. Res. Vet. Sci. 20, 197-200.

\section{DESCRIPTION OF FIGURES}

Fig. (1): Subcutaneous muscle bundles of $\mathrm{g}$. pig showing severe degeneration and necrosis, subcutaneous infection. (H.E. $X 400$ ).

Fig. (2): Lung of 9.pig showing congestion, extravasation and pericapillary cellular reaction, infection by scarification. (H.E. X 160).

Fig. (2): Precrural lymph node of 9.pig showing congested blood vessels and haemorrhages, intramuscular infection (H.E. $\times$ 400).

Fig. (4): Liver of 9.pig showing focal area of coagulative necrosis, intramuscular infection. (H.E. X 100).

Fig. (5): Adrenal of 9.pig showing oedema and haemorrhage in the cortico - medullary ureas infection by scarification (H.E. 250). 


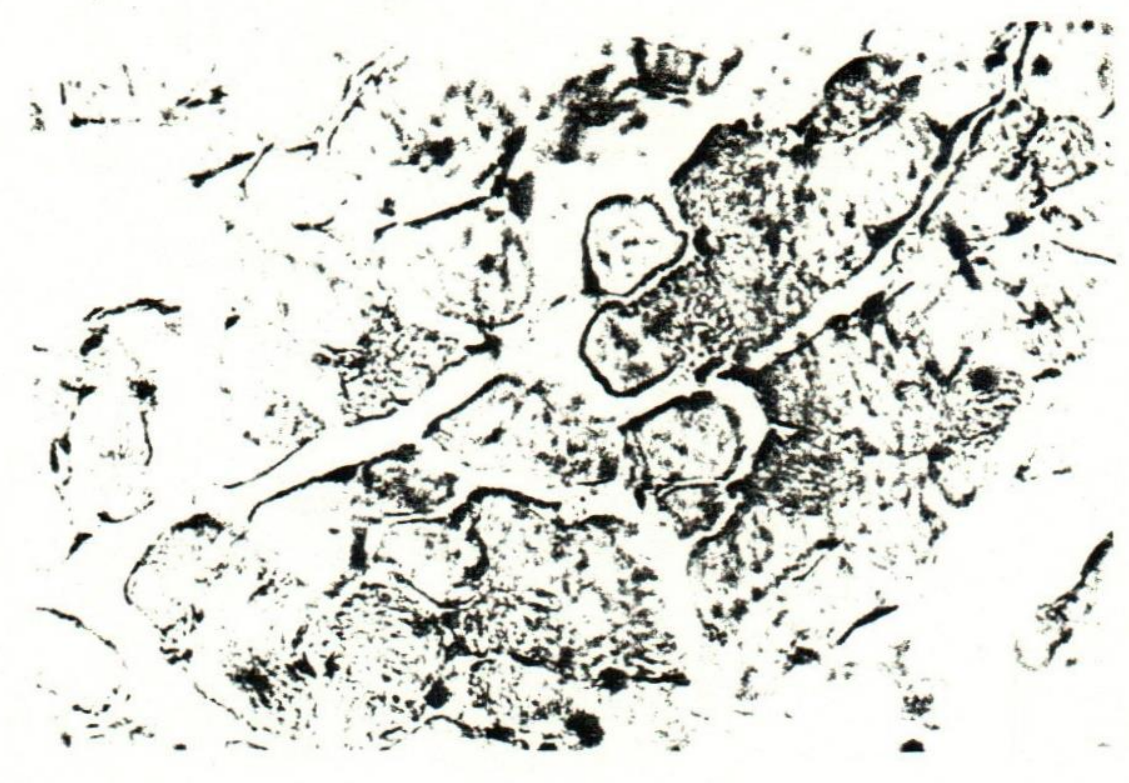

FIG, (1)

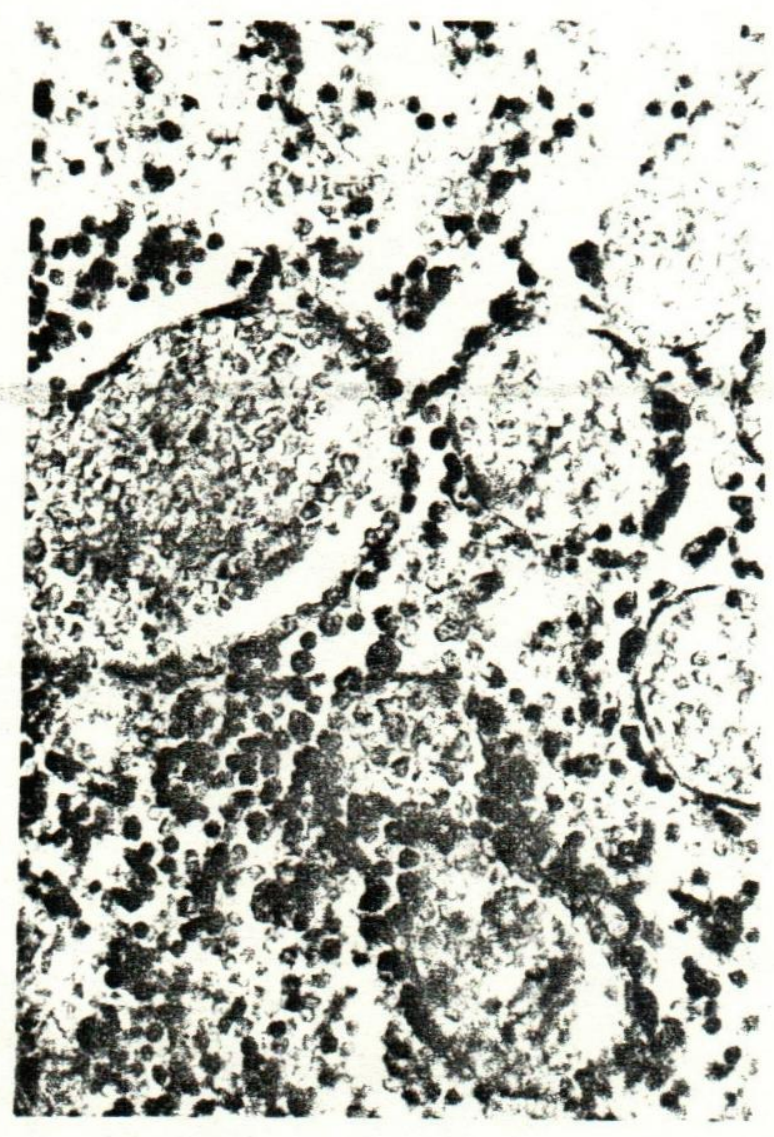

2.

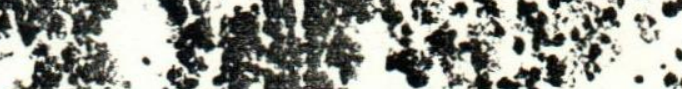

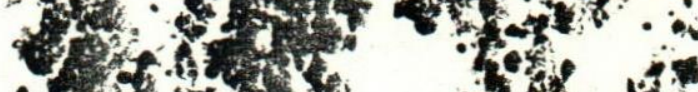

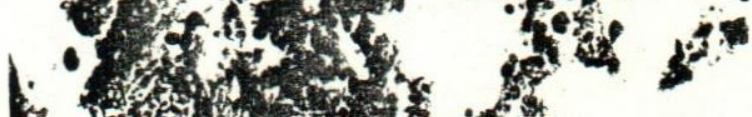

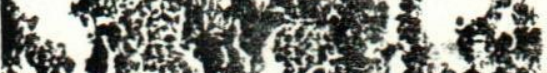

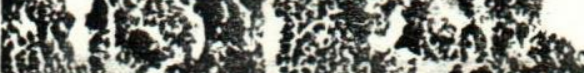
Mith

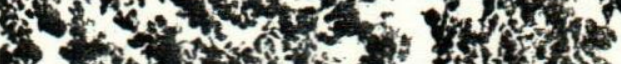

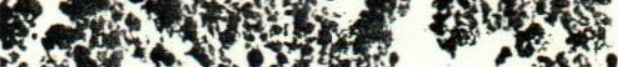

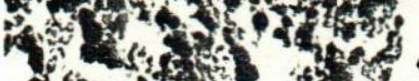

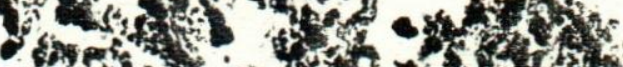
Ands 5 of (2)

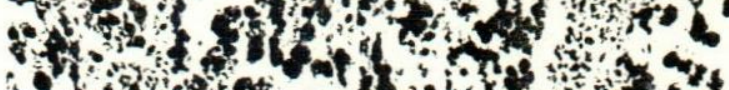

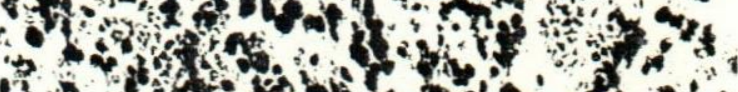

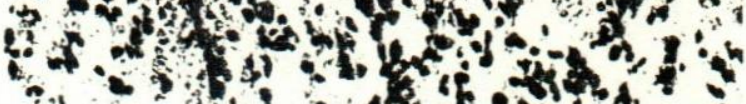
- 25 क of

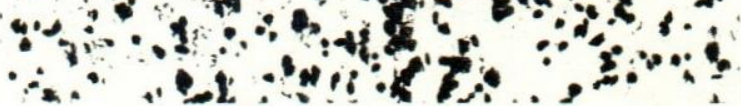




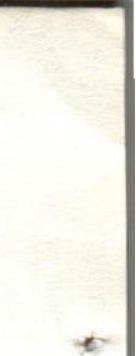

2 


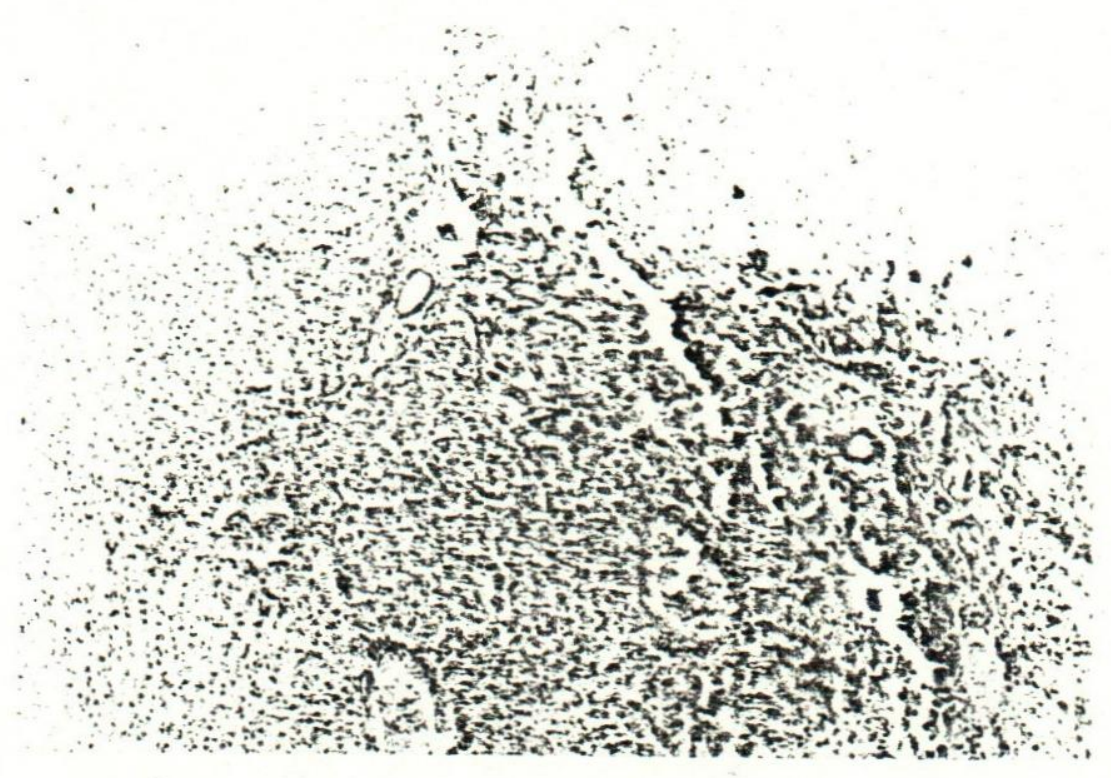

FIG. (4)

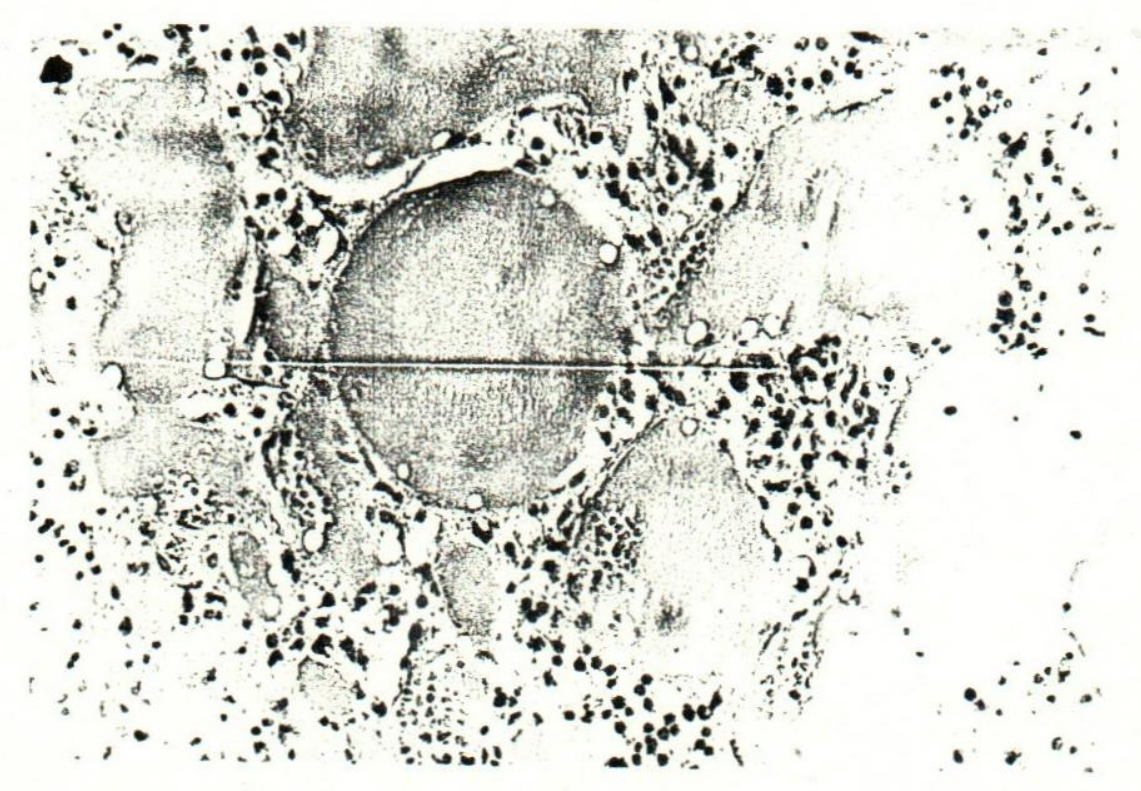

FIG. (5) 
